\title{
AS AMARRAS DO NEOCONSTITUCIONALISMO E AS PERSPECTIVAS DO NOVO CONSTITUCIONALISMO LATINO-AMERICANO: ELEMENTOS PARADIGMÁTICOS PARA A EFETIVAÇÃO DOS DIREITOS HUMANOS DOS POVOS DA AMÉRICA DO SUL
}

\section{THE OBSTACLES OF NEOCONSTITUTIONALISM AND THE PERSPECTIVES OF THE NEW LATIN AMERICAN CONSTITUTIONALISM: PARADIGMATIC ELEMENTS FOR THE REALIZATION OF THE HUMAN RIGHTS OF THE PEOPLES OF SOUTH AMERICA}

Evilhane Jum Martins

Doutoranda em Direito pela Universidade Federal do Pará - UFPA. Mestre em Direito pela Universidade Federal de Santa Maria - UFSM. Graduada em Direito pela Universidade da Região da Campanha - URCAMP.

E-mail: evilhane_martins@hotmail.com

Jerônimo Siqueira Tybusch

Doutor em Ciências Humanas pela Universidade Federal de Santa Catarina - UFSC. Mestre em Direito pela Universidade do Vale do Rio dos Sinos - UNISINOS. Graduado em Direito pela Universidade de Santa Cruz do Sul - UNISC.

E-mail: jeronimotybusch@ufsm.br

Giane da Silva Ritter Morello

Mestre em Direito pela Universidade Federal de Santa Maria - UFSM. Graduada em Direito pela Universidade Federal de Santa Maria - UFSM. E-mail: sr.giane@gmail.com

Recebido em: 10/03/2017

Aprovado em: 29/06/2017

Doi: $10.5585 /$ rdb.v17i7.626

RESUMO: A presente pesquisa trata da análise comparada dos movimentos constitucionais designados como Neoconstitucionalismo e Novo Constitucionalismo Latino-americano para a efetivação dos direitos humanos dos povos sul-americanos. Inter-relacionando o Neoconstitucionalismo com o processo de colonialidade, bem como o Novo Constitucionalismo Latino-americano com construções sociojurídicas fidedignas à realidade do continente, objetivase analisar novas perspectivas de efetivação dos direitos humanos dos povos sul-americanos a partir do movimento constitucional denominado como Novo Constitucionalismo Latinoamericano. Para tanto, parte-se da seguinte problemática: Quais os limites e possibilidades para a construção de novas percepções acerca dos direitos humanos dos povos sul-americanos a partir das inovações próprias do novo constitucionalismo latino-americano? A fim de responder tal questionamento a pesquisa em questão sustenta-se metodologicamente na perspectiva dialética, a partir de uma análise que engloba tese e antítese, conectando ares do saber como Direito Constitucional, Direitos Humanos, Sociologia e Geopolítica da América do Sul. Como procedimento adotou-se a pesquisa bibliográfica e documental e a técnica empregada é a 
construção de fichamentos e resumos estendidos. Como resultado, verifica-se que construções sociojurídicas próprias da América do Sul são capazes de garantir a efetividade de direitos humanos positivados em textos constitucionais comprometidos com a realidade sul-americana: tarefa fadada ao Novo Constitucionalismo Latino-americano.

Palavras-Chave: Neoconstitucionalismo. Novo Constitucionalismo Latino-americano. Direitos Humanos. Povos sul-americanos.

ABSTRACT: This research deals with the comparative analysis of the constitutional movements designated as Neoconstitutionalism and New Constitutionalism Latin American to the realization of human rights of South American peoples. Interrelating the Neoconstitutionalism with Coloniality process, as well as the New Constitutionalism Latin American with social and legal buildings reliable reality of the continent, the objective is to analyze new opportunities for realization of human rights of South American people from the so-called constitutional movement New Constitutionalism as Latin American. Therefore, part is the following issues: What are the limits and possibilities for the construction of new insights about the human rights of South American peoples from their own innovations of the new constitutionalism Latin American? In order to answer this question the research in question holds up methodologically in dialectical perspective, from an analysis that includes thesis and antithesis, connecting air of knowledge as Constitutional Law, Human Rights, Sociology and geopolitics of South America. As a procedure adopted the bibliographical and documentary research and the technique is to build files and extended abstracts. As a result, it appears that own social and legal buildings in South America are able to ensure the effectiveness of human rights positivized in constitutional texts committed to the South American reality: fated task to the New Constitutionalism Latin American.

Keywords: Neoconstitutionalism. New Latin American Constitutionalism. Human Rights. South American People.

SUMÁRIO: Introdução; 1. Neoconstitucionalismo e processo de colonialidade: implicações à efetivação dos direitos humanos dos povos sul-americanos; $1.1 \mathrm{O}$ Neoconstitucionalismo e sua inter-relação com o processo de colonialidade na América Latina; $1.2 \mathrm{O}$ Neoconstitucionalismo e seus reflexos nos direitos humanos do povos sul-americanos; 2. O Novo Constitucionalismo Latino-americano enquanto pilar sociojurídico para os direitos humanos dos povos sulamericanos; $2.1 \mathrm{O}$ protagonismo emancipatório do Novo Constitucionalismo Latino-americano; 2.2 O Novo Constitucionalismo Latino-americano enquanto ferramenta legitimadora dos direitos humanos dos povos sul-americanos; Conclusão; Referências.

\section{INTRODUÇÃO}

A América do Sul no curso de sua história possui sucessivos processos de colonização e, mais contemporaneamente, o processo de colonialidade. Nesse contexto, identificando o Direito e os movimentos constitucionais enquanto elementos essenciais para a construção socioeconômica do continente tratar-se-á da disseminação do neocontitucionalismo encampado pelos países sulamericanos como substrato jurídico para instalação do processo de colonialidade. Tal fato tem implicação direta na inefetividade dos direitos humanos dos povos sul-americanos.

Isso se afirma em razão de o neoconstitucionalismo possuir formação de bases europeias, o qual foi incorporado/importado pelos países sul-americanos sem atenção às peculiaridades e realidades locais. O hiato decorrente entre modelo teórico-jurídico e multirealidade do continente é consequência direta e intransponível na efetivação de direitos humanos. 
Diante disso, é cogente discutir-se novas perspectivas para efetivação dos direitos humanos dos povos tradicionais locais, diante de sua multietnicidade e diversidade, tendo como lente de partida o próprio local de onde de observa a realidade.

Nesse sentido, objetiva-se de modo geral analisar novas perspectivas de efetivação dos direitos humanos dos povos sul-americanos a partir do movimento constitucional denominado como Novo Constitucionalismo Latino-americano, levando em conta a inefetividade do modelo neoconstitucional incorporado pelos países sul-americanos até então.

Frente a tais considerações, a presente pesquisa sustenta-se na seguinte problemática: quais os limites e possibilidades para a construção de novas percepções acerca dos direitos humanos dos povos sul-americanos a partir das inovações próprias do Novo Constitucionalismo Latino-americano?

A fim de responder o presente questionamento, a metodologia utilizada obedece ao trinômio: Teoria de Base/Abordagem, Procedimento e Técnica. Como teoria de base e abordagem, perspectiva dialética, a partir de uma análise que engloba tese e antítese, conectando ares do saber como Direito Constitucional, Direitos Humanos, Sociologia e Geopolítica da América do Sul, realizando conjecturas e hipóteses para a compreensão transdisciplinar de uma problemática que é jurídica, mas não tão somente jurídica. Como procedimento adotou-se a pesquisa bibliográfica e documental e a técnica empregada é a construção de fichamentos e resumos estendidos.

Dessa forma, no primeiro capítulo analisa-se o Neoconstitucionalismo e suas características frente ao processo de colonialidade, bem como as razões pelas quais não consegue solver as demandas e anseios dos povos sul-americanos ocasionando a inefetividade dos direitos humanos de tais povos. Posteriormente, no segundo capítulo, averigua-se o Novo Constitucionalismo Latino-americano e seu protagonismo emancipatório enquanto possibilidade de ferramenta jurídica para a efetivação dos direitos humanos dos povos tradicionais.

Como resultado, verifica-se que construções sociojurídicas próprias da América do Sul, que levem em consideração as identidades e necessidades de seus povos, são capazes de garantir a efetividade de textos constitucionais comprometidos com a realidade sul-americana. Nesse ínterim, o Novo Constitucionalismo Latino-americano corresponde aos anseios dos povos sulamericanos através do reconhecimento dos direitos humanos inerentes às peculiaridades $\mathrm{e}$ realidade do continente, garantindo sua efetividade.

\section{NEOCONSTITUCIONALISMO E PROCESSO DE COLONIALIDADE: IMPLICAÇÕES À EFETIVAÇÃO DOS DIREITOS HUMANOS DOS POVOS SUL- AMERICANOS}

O capítulo que inaugura o presente ensaio analisa a assimilação do neocontitucionalismo nos países sul-americanos a partir da ótica do processo de colonialidade. Para tanto, utiliza-se da teoria de Aníbal Quijano acerca dos processos de colonização que foram calcados a partir da descoberta das Américas e que ensejaram a formação do padrão de poder mundial e do surgimento da modernidade/globalização como ponto de partida para fomentar o estudo. Assim, evidencia-se o Neoconstitucionalismo nos países sul-americanos como substrato jurídico que propiciou e/ou fomentou a manutenção do padrão de poder subserviente no continente, bem como do processo de colonização e, posteriormente, do processo de colonialidade ao decorrer da história.

Dessa abordagem somada às relações de poder que permeiam o cenário nos países sulamericanos, evidencia-se a incapacidade desse modelo constitucional em dar respostas e satisfazer as demandas e anseios dos povos originários locais. Isso porque, o seu modo de absorção pelos países sul-americanos, resultou, invariavelmente, na dissonância das suas características com as peculiaridades locais, implicando na inefetividade dos direitos humanos 
aos povos sul-americanos, razão pela qual é cogente se pensar novas perspectivas para a efetivação dos direitos humanos a partir da ótica do próprio continente.

\subsection{O Neoconstitucionalismo e sua inter-relação com o processo de Colonialidade na América Latina}

O processo de colonialidade é, em breve síntese, um mecanismo de produção e reprodução dos aparatos de dominação de povos, seus bens e suas culturas em benefício daquele que impõe seu poder e suposta superioridade, calcado na unicidade de ideia de desenvolvimento sob parâmetros eurocêntricos. Com base na teoria de Quijano é possível observar o surgimento da modernidade do fenômeno da globalização a partir do que o autor convenciona chamar de padrão de poder que emergiu quando da descoberta e colonização das Américas pelos europeus e que está imbricado com a formação das configurações do sistema-mundo-global ( 2005).

Esse padrão de poder está solidificado sob três pilares de sustentação, quais sejam, o capitalismo colonial/moderno - como mecanismo de exploração social; o eurocentrismo hegemônico - como controle das subjetividades; e, por fim, a colonialidade do poder, como o instrumento mais eficiente de dominação social até então exercido. Quijano em sua teoria, desenvolve a ideia de que a "colonialidade do poder" é uma construção mental de dominação europeia pautada em critérios de "raça", pela qual, imputa-se uma condição natural de inferiorização dos povos dominados, inclusive, sob suas perspectivas cognitivas/subjetivas (eurocentrismo) e atribuiu-se critérios de hierarquias e papéis sociais que incidiram na configuração da geografia social do capitalismo que se desenvolveu, e que justificou o processo de colonização, como ponto de partida para a configuração mundial hodierna (2005).

Essa teoria - de Quijano, que teve seu embrionário com a descoberta das Américas, se desdobra em novas facetas ao longo do curso da história e pode ser observada sobre os mais diversos vieses, sobretudo quando se trata de estender a lente de observação sobre o território da América Latina. Atualmente, os critérios de dominação desse sistema-mundo-global, em um processo de colonialidade, apresentam-se vinculados ao capital, e aos espaços geográficos calcados, portanto, em critérios ditos geoeconômicos. Elegido, dentro do contexto da América Latina, os países sul-americanos como palco de análise no presente ensaio, a abordagem do processo de colonialidade se dará a partir das perspectivas do constitucionalismo, das imbricações aos direitos humanos e aos povos sul-americanos.

Constitucionalismo, colonialismo e colonialidade, são matizes de uma mesma encruzilhada das relações de poder. Partindo desse pressuposto, é salutar ter límpida a ideia de que a existência de uma Constituição escrita é característica ínsita do constitucionalismo moderno. No entanto, é prescindível que haja um documento escrito para se afirmar que um Estado possui Constituição, ou Direito. Lassale, de forma contundente, infere que Constituição é o elemento que se forma pelo exercício dos fatores reais de poder daquele dado momento histórico em curso, e diz que

[...] todos esses princípios de Direito público, esses pergaminhos, esses foros, estatutos e privilégios reunidos formavam a Constituição do país, sem que todos eles, por sua vez, fizessem outra coisa que exprimir, de um modo simples e sincero, os fatores reais do poder que regia no país.

Assim, pois, todos os países possuem ou possuíram sempre, e em todos os momentos da sua história uma Constituição real e verdadeira. A diferença nos tempos modernos - e isto não deve ficar esquecido, pois tem muitíssima importância - não são as Constituições reais e efetivas, mas sim as Constituições escritas nas folhas de papel.

De fato, na maioria dos Estados modernos, vamos aparecer, num determinado momento da sua história, uma Constituição escrita, cuja missão é a de 
estabelecer documentalmente, numa folha de papel, todas as instituições e princípios do governo vigente. " (LASSALE, 2001, p.56)

Quer dizer, os momentos históricos são marcados por determinados fatores reais de poder que regulam as relações sociais, culturais, políticas, econômicas, etc., de modo que a Constituição de forma escrita é mero diferencial das Constituições modernas. Portanto, o poder é elemento essencial de regulação/emancipação/subjugação/violência, e está presente como um elo nas discussões das temáticas do constitucionalismo, da América Latina e do processo de colonialidade.

Santos indaga-se e se dispõe a esboçar certa definição geral para esse elemento que carrega no seu cerne forte impacto sob as relações globais. Desse modo, assim o define:

O que é então poder? A um nível muito geral, o poder é qualquer relação social regulada por uma troca desigual. É uma relação social porque a sua persistência reside na capacidade que ela tem de reproduzir desigualdade mais através da troca interna do que por determinação externa. As trocas podem abranger virtualmente todas as condições que determinam a acção e a vida, os projectos e as trajectórias pessoais e sociais, tais como bens, serviços, meios, recursos, símbolos, valores, identidades, capacidades, oportunidades, aptidões e interesses. No relativo às relações de poder, o que é mais característico das nossas sociedades é o facto de a desigualdade material estar profundamente entrelaçada com a desigualdade não material, sobretudo com a educação desigual, a desigualdade das capacidades representacionais/comunicativas e expressivas e ainda a desigualdade de oportunidades e de capacidades para organizar interesses e para participar autonomamente em processos de tomada de decisões significativas. (SANTOS, 2011, p. 267)

O poder como assim descrito por Santos é perfeitamente observado em território latinoamericano, sobretudo, quanto às questões relativas ao Direito. A colonização clássica sob os critérios do padrão de poder do sistema-mundo-global, da teoria de Quijano, sobretudo da colonialidade do poder e do eurocentrismo, modulado e/ou reinventado, igualmente nas vestes modernas, foi responsável por aniquilar as diversidades e capacidades dos povos dominados em dimensões múltiplas, tornando aquilo que é produzido pelos dominadores única fonte viável, verdadeira e superior. Sob essa premissa, reside a absorção ou a subsunção dos países latinoamericanos às formas de direito e padrões de vida ditados pelos modelos eurocêntricos.

A partir disso, após o curso da colonização clássica, os diversos momentos históricos perpassados pelos países latinos, sobretudo dos regimes ditatoriais, os processos de redemocratização foram marcados pela incorporação do fenômeno do Neoconstitucionalismo às embrionárias Constituições. Esse fenômeno além de ter sua origem e formulação nas bases e concepções europeias, foi encampado em solo sul-americano no contexto do que convencionouse chamar de "colonialismo interno" pelo qual, segundo Gonzalez Casanova

"os Estados de origem colonial e imperialista e suas classes dominantes refazem e conservam as relações coloniais com as minorias e as etnias colonizadas que se encontram no interior de suas fronteiras políticas. $\mathrm{O}$ fenômeno repete-se uma ou outra vez depois da queda dos impérios e da independência política dos Estadosnação com variantes que dependem da correlação de forças dos antigos habitantes colonizados e colonizadores que conseguiram a independência.

Uma objeção menor ao uso da categoria de colonialismo interno consistiu em afirmar que em todo caso o que existe é um semicolonialismo ou neocolonialismo interno, o qual em parte é certo se por tais tomam-se as formas de dependência e exploração colonial mediante o emprego (ou a associação) de 
governantes nativos que pretendem representar as etnias de um Estado-nação" (GONZÁLEZ CASANOVA, 2007,09).

É nesse contexto que o neoconstitucionalismo é incorporado como modelo jurídico no ordenamento dos países sul-americanos, e como tal, constitui substrato fértil para a proliferação do processo de colonialidade e da perpetuação do poder de padrão do sistema-mundo-global sobre o continente, sobretudo, em razão das suas características embrionárias. Isso porque, o Neoconstitucionalismo, é, pois, uma reação a ordem positivista legalista precedente, a qual tinha como características inerentes a cisão entre direito, justiça e moral; a onipotência e exaltação do legislador (Estado); o excesso de formalismo jurídico; critérios formais de validade da norma, etc., e que foi elemento essencial para a ascensão dos regimes totalitários nazi-facistas, e, por conseguinte, o cometimento das atrocidades aos direitos humanos das guerras do século XX. Disso, tornou-se imprescindível promover uma nova releitura das bases, e a reaproximação entre direito e moral, a fim de formular um direito de cunho mais humano.

Assim, o Neoconstitucionalismo inaugura os direitos humanos como aparato que emite reflexos a todos os demais vieses das relações, isso porque, insere o homem (ser humano) no centro do Direito. Nesse diapasão, Fernandes afirma que esse modelo se desenvolve a partir de uma ótica social, com o objetivo de suplantar as mazelas de uma sociedade órfã e carente da materialização dos direitos fundamentais minimamente exigíveis para uma subsistência digna (2014), culminando, portanto, na formalização de um Estado Social de Direito.

Em que pese isso, o fenômeno do Neoconstitucionalismo tem suas bases de formação elementos arraigados aos mesmos sedimentos propulsores do positivismo jurídico, ou seja, advindos da revolução francesa e revolução americana e suas tradições constitucionais. Imediatamente é possível vislumbrar que o constitucionalismo contemporâneo tem na sua essência fundamentalmente ideologias e preceitos de cânones liberais e individuas. Nesse sentido, imprescindível frisar as lições de Figueiredo quanto a formação do Direito e das bases constitucionais a partir da Modernidade:

Neste novo mundo, a comparação e o exame atento das diferenças irão constituir as mais nobrestarefas da ciência, pois estas tarefassão descrever a realidade como ela é, tanto quanto refletir sobre as possibilidades de assim fazê-lo, controlando os níveis de incertezado que se buscou compreender. Para o direito político dos últimos duzentos anos, um pouco diferentemente, os fundamentos ideais e as instituições cujos problemas são previamente desenhados constituem a „matéria ${ }^{\text {ee }}$ do pensamento. Esta „matéria ${ }^{\text {ee }}$ pode ser organizada como um sistema, como uma ordem, pois é posta em discussão sobre o conceito de constituição, ainda que as grandes formações políticas e ainda mais as econômicas, venham a ensejar ferramentas diversas para sua exploração (2015, p. $33)$.

A Revolução Francesa atendia aos interesses das classes burguesas, e buscava reformas estruturais que "responda a determinados valores preteridos pela sociedade estamental e o sistema de privilégios que a ela é inerente" (JULIOS-CAMPUZANO, 2009, p.25). De outro lado, tradição americana tinha aspirações antiestatalistas, e pautava-se em três grandes elementos: limitação ao poder estatal (sistema de equilíbrios e contrapesos - check and balances), garantias fundamentais (sobretudo, direitos e liberdades individuais) e uma dimensão garantista através do controle de constitucionalidade pelo olhares fiscalizadores dos juízes, com objetivo precípuo de criar espaços de liberdades baseada em direitos civis e o pleno exercício das autonomias individuais e privadas nas relações, e a redução a patamares mínimos de intervenção pública do Estado (JULIOS-CAMPUZANO, 2009). 
Nesse sentido, indaga-se se realmente o neoconstitucionalismo se propõe a romper com a ordem anterior, ou, representa tão somente uma forma diversa de manter os interesses e privilégios das classes dominantes, bem como, dos direitos individuais e da propriedade privada; "se perguntan si en realidade hay algo nueno em el Neoconstitucionalismo, o si más bien se trata de una etiqueta vacía, que sierve para presentar bajo um nuevo ropaje cuestiones que antaño se explicaban de otra manera" (CARBONELL, 2007, p. 09). Ao que indica, a resposta adequada é que, em que pese traga uma certa rematerialização das normas, anunciando um catálogo de direitos e garantias sociais, o anúncio da supremacia dos direitos humanos, o vértice central da tutela do constitucionalismo contemporâneo são os direitos e liberdades individuais, bem como o direito de propriedade privada. Tal acepção evidencia sua essência liberal-burguesa.

Entretanto, é esse modelo de carta constitucional que passou a ser incorporado pelos países latino-americanos a partir da redemocratização pós períodos ditatoriais. Um modelo de Neoconstitucionalismo importado, de bases euro-americanas que reflete a hegemonia de um Direito supostamente em superioridade e em benefício da universalidade e da isonomia, sobretudo, após as ocorrências das guerras do século XX. Um modelo que não reflete, tampouco reconhece as nuances, realidades e diversidades do continente latino-americano, visto que, gestacionado para atender as necessidades e demandas de onde foi gerado.

Por fim, se conforme Lassale, inicialmente citado, dizia que as constituições são resultadas dos fatores reais de poder, o Neoconstitucionalismo incorporado nas vestes euroamericanas pelas Cartas Constitucionais dos povos latino-americanos, é resultado dos fatores reais de poder externos às suas realidades. Isto é, impostos pelo padrão de poder do sistemamundo-global, da colonialidade do poder, do eurocentrismo. Obviamente, é inegável que o Neoconstitucionalismo trouxe avanços memoráveis ao Direito, mas é também imprescindível desromantizá-lo sob a ótica latino-americana, para observar seus vieses de colonialidade, a fim de descortinar suas incapacidades de sanar e dar as respostas as demandas e necessidades do próprio continente, sobretudo, no que tange aos direitos dos povos tradicionais, como será abordado no item seguinte.

\subsection{O Neoconstitucionalismo e seus reflexos nos Direitos Humanos do povos Sul- Americanos}

O Neoconstitucionalismo, enquanto observado pelas lentes da colonialidade, e, enquanto modelo e padrão de regulação importados sob critérios de superioridade, em atenção a realidades outras que não as latino-americanas, é fenômeno incapaz de concretizar direitos, direitos humanos e dar respostas as demandas e anseios dos povos originários do continente latinoamericano. Isso porque, visto por intermédio da ótica do Sul Social ${ }^{1}$, os direitos sociais e as políticas sociais como ação positiva do Estado pouco se materializam ou não se materializam, permanecendo inertes no viés formal da Carta Constitucional.

\footnotetext{
${ }^{1}$ Santos ao discorrer nos seus trabalhos acerca das Epistemologias dos Sul demonstra as diferenças imperantes entre o Norte e o Sul, desprezando aspectos tão somente geográficos. O Sul metaforicamente é concebido como um campo epistêmico, com vistas a reparar os danos e experimentado historicamente pelo capitalismo nas suas relações coloniais com o mundo. "A sobreposição não é total porque, por um lado, no interior do Norte geográfico classes e grupos sociais muito vastos (trabalhadores, mulheres, indígenas, afrodescendentes, mulçumanos) foram sujeitos à dominação capitalista e colonial e, por outro lado, porque no interior do Sul geográfico houve sempre as 'pequenas Europas', pequenas elites locais que beneficiaram da dominação capitalista e colonial e que depois das independências a exerceram ou continuaram a exercer, por suas próprias mãos, contra as classes e grupos sociais subordinados. A ideia central é, como já referimos, que o colonialismo, para além de todas as dominações por que é conhecido, foi também uma dominação epistemológica, uma relação extremamente desigual de saber-poder que conduziu a supressão de muitas formas de saber próprias de povos e/ou nações colonizados. A epistemologias do Sul são o conjunto de intervenções epistemológicas que denunciam essa supressão, valorizam os saberes que resistiram com êxito e investigam as condições de um diálogo horizontal entre conhecimentos. ” (2010, p.19).
}

Revista de Direito Brasileira | São Paulo, SP | v. 17 | n. 7 | p. 90 - 107 | Mai./Ago. 2017 
Como visto anteriormente, isso se explica especialmente em razão da sua raiz de formação. Ou seja, o Neoconstitucionalismo foi pensado e elaborado sobre a realidade e para atender as necessidades europeias do pós-guerra. Portanto, se resguarda ao objetivo precípuo de conceder respostas e soluções adequadas às demandas que emergiram daquele contexto, tão e somente. Em que pese isso, esse modelo refletiu nas constituições latino-americanas formuladas após os regimes ditatoriais sem a devida atenção às peculiaridades do continente.

Inegável que o desenvolvimento da sociedade latino-americana após as invasões e colonização hispânica e portuguesas sempre se deu, reiteradamente, refletindo os ditames dos padrões de vida e cultura euro-americanos. Isso é reflexo das múltiplas assumidas pela colonialidade ao longo da história no continente. A importação e incorporação do modelo/fenômeno do Neoconstitucionalismo como concebido em solo europeu assume novos contornos dessa colonialidade, e implica em não efetivação dos direitos humanos dos povos tradicionais latino-americanos.

A dificuldade de perceber a ineficácia desse modelo em garantir e efetivar os direitos humanos de um modo geral em solo latino-americano, sobretudo, no que concerne aos povos originários, reside essencialmente na cegueira imposta pelo padrão de poder do sistema-mundoglobal, da colonialidade, assumidos e exercidos no curso da sua história, e "as consequências da cegueira manifestam-se na representação distorcida das consequências" (SANTOS, 2011, p. 244), isso porque,

[...] aquilo que interaccionalmente surge como determinação externa de uma dada relação de poder é quase sempre uma manifestação da mesma constelação de poder num dos seus elos anteriores e mais remotos. É por isso que as pessoas frequentemente aceitam como sendo troca igual aquilo que, de facto, é uma troca desigual. É evidente que a máscara de igualdade que o poder assume é uma ilusão, mas, por ser necessária enquanto ilusão, tem o seu 'quê' de verdade. (SANTOS, 2011, p. 267)

Essas trocas desiguais, aceitas pela cegueira como trocas iguais, estão assentes na discrepância de realidades. Isto é, há um paradoxo entre as realidades europeias lá dispostas e que fundamentaram as doutrinas, filosofias e teorias dos pensadores do fenômeno do neoconstitucionalismo, e a realidade do continente latino-americano, cuja realidade local em nada se assemelha, mas que se subsumiu a esse fenômeno sem contestação, tendo como consequência, a negação de direitos a parcelas significativas dos povos.

Os países sul-americanos, na sua maioria, carregam na bagagem da sua história, o ranço da colonização, da exploração, da subjugação cultural, do aculturamento. De outro lado, é enriquecido pela miscigenação, diversidade étnica, a diversidade cultural, e, em contrapartida, assolado pelas desigualdades sociais, o neocolonialismo, entre outras tantas peculiaridades das quais o Neoconstitucionalismo não é capaz de entender, compreender, e tampouco responder. Porque, além de trazer no bojo a características liberais-burguesas, também não é fidedigno à realidade local e

[...] em qualquer de seus modelos escritos, a Constituição contemporânea deverá necessariamente se voltar no sentido de apreensão desta nova estrutura social, sob pena de estarmos diante de uma superlei não inspirada na própria realidade para a qual será destinada. Vale ressaltar que, nesse caso, com o passar do tempo, o divórcio entre a Constituição escrita e a realidade provocará um Hiato Constitucional e, em consequência, a necessidade de convocação de uma Assembléia Constituinte, a qual, no exercício do Poder Constituinte, elaborará novo texto, agora representativo dos valores sociais existentes. (DANTAS, 2009, p. 314) 
E foi este hiato constitucional provocado por um modelo de Neoconstitucionalismo importado (eurocêntrico) pelas nações latino-americanas destoante da realidade local aliados aos fatores econômicos do capitalismo neoliberal que exsurgem nas décadas de 1980 e 1990, que fez surgir o que se conhece hoje por "novo constitucionalismo latino-americano", o qual será melhor abordado no capítulo seguinte. O que se pode compreender por "hiato Constitucional" a que o autor faz referência é a incapacidade da norma (constituição) de dar efetividade dos direitos aos seus destinatários, especialmente -nesse trabalho- aos direitos humanos dos povos tradicionais, e a completa dissociação da norma com a realidade local.

De outro lado, ainda importante salientar que o constitucionalismo tradicional é assente na figura do Estado Nacional de formulação eurocêntrico, o qual foi concebido sob a acepção da unidade dos cidadãos do país no conceito de "nação", em critérios de igualdade, uniformidade e homogeneidade. Somando a isso, ainda há o exercício de um ufanismo exacerbado pela imputação das nacionalidades pátrias, das línguas nacionais. Ou seja, uma pátria com língua nacional, corresponde a uma identidade nacional dentro de fronteiras artificiais. Essa conformação de Estado, que dá respaldo ao Neoconstitucionalismo, aniquila e extermina a diversidade sob uma pretensa igualdade formal, uma unidade identitárias, as quais, não atendem a dimensão da diversidade e das plúrimas formas de vidas dos povos originários da América Latina.

Essa concepção introduziu identidades forjadas aos dominados, negando e ocultando sujeitos. Além disso, fomentou e justificou todo o processo de colonização e aculturamento indígena dos países latino americanos. Ou seja, o Neoconstitucionalismo assente no modelo de Estado-nação, firmado sob os preceitos da igualdade e unidade, incorporados pelos países latinos, importa na negação das diferenças, pautada na superioridade civilizatória do estilo de vida europeu, o que resulta na invisibilidade das heterogeneidades e na produção de sujeitos ocultados, sujeitos negados ou sujeitos invisíveis. Assim,

Temos aí a construção de nacionalidades sobre as preexistentes, forjando-se "tradições", "mitos" nacionais, uma "língua pátria", etc. Com isso, as identidades são sufocadas pela uniformização e as diferenças são rejeitadas mediante artificialismos formadores dos Estados Nacionais de padrão europeu que acabam por justificar a superioridade de determinada culturas sobre outras [...]. (FERNANDES, 2014, p. 59)

É notável que o desenvolvimento das constituições nos dados momentos históricos é imprescindível para a compreensão do momento presente e para projeções do futuro. $\mathrm{O}$ neoconstitucionalismo com suas raízes euro-americanas e liberais produziu reflexos nas cartas constitucionais latino americanas. Entretanto, a divergências histórica de suas realidades e inadequações suprime a capacidade desse modelo em satisfazer os anseios sociais, e, sobretudo, de efetivar os direitos humanos dos povos tradicionais, visto que, sufoca a diversidade, nega sujeitos em prol de uma identidade uníssona e uma igualdade formal forjada.

Sob tais aspectos, as linhas anteriores são capazes de induzir reflexões críticas acerca da história constitucional latino-americana e sua íntima relação com o processo de colonialidade.

\footnotetext{
${ }^{2}$ Segundo Bragato e Castilho não há um consenso entre os estudioso acerca da denominação do movimento constitucional latino-americano dessas últimas décadas. As autoras fazem apontamentos das mais diversas denominações utilizadas pelos estudiosos afirmando "como aponta Brandão (2013), diversas são as denominações apontadas, Novo Constitucionalismo Latino-Americano (Viciano e Dalmau), Constitucionalismo Mestiço (Baldi), Constitucionalismo Andino e Constitucionalismo Pluralista Intercultural (Antônio Carlos Wolkmer), Neoconstitucionalismo Transformador (Santamaría), Constitucionalismo Pluralista (Raquel Fajardo), Constitucionalismo Experimental ou Constitucionalismo Transformador (Boaventura de Souza Santos), Constitucionalismo da Diversidade (Uprimmy) e outros." (2014).
} 
Amparado em estruturas de poder moldadas sob princípios eurocêntricos, a história constitucional da América Latina nasce a partir de uma adesão não voluntária do neoconstitucionalismo em total desconformidade com as identidades e necessidades de seus povos.

Nesse sentido, pode-se afirmar que a geopolítica constitucional da América Latina, é permeada por duas características precípuas: a primeira diz respeito ao ímpeto social dos povos latino-americanos por adequar a ordem constitucional à realidade vivida no continente e às necessidades prementes dos cidadãos latinos; a segunda consubstancia-se na influência direta que os países colonizadores exerceram na formação jurídica dos países que compõem o território latino-americano, obtendo sequência em meio a um processo de colonialidade que consagra no momento atual sua essência desenvolvimentista ${ }^{3}$.

Por derradeiro, é imprescindível compreender que não se pretender negar as benesses que o neoconstitucionalismo projetou na seara do Direito, mas compreender esse fenômeno a partir da realidade do Sul Social, dos países latinos, como faceta de colonialidade, que o torna incapacitante na efetivação dos direitos humanos dos povos originários. Em contrapartida, pretende-se discorrer nas próximas linhas acerca do movimento constitucional denominado como Novo Constitucionalismo Latino-americano enquanto paradigma para efetivação dos diretos humanos dos povos tradicionais.

\section{O NOVO CONSTITUCIONALISMO LATINO-AMERICANO ENQUANTO PILAR SOCIOJURÍDICO PARA OS DIREITOS HUMANOS DOS POVOS SUL-AMERICANOS}

As reflexões efetuadas anteriormente dão conta de induzir criticamente novas formas de pensar no que concerne ao advento do neoconstitucionalismo na América Latina, sua interrelação com o colonialismo interno e a formação de bases para o processo de colonialidade calcado em diretrizes geoeconômicas, principalmente em países da América do Sul. Por consistir em um aparato constitucional incongruente com a realidade e necessidades, direitos humanos positivados constitucionalmente carecem de efetivação e, não raras vezes, deixam de ser considerados pelos aportes constitucionais tendo em vista que as bases neoconstitucionais distinguem-se da realidade latino-americana, sobretudo da realidade da América do Sul.

Levando em conta tais aspectos, o desenvolvimento deste capítulo presta-se a evidenciar a representatividade própria do Novo Constitucionalismo Latino-americano para os povos sulamericanos, enquanto precursor da efetivação constitucional de direitos humanos comprometidos com as identidades e necessidades dos povos da América do Sul, sobretudo.

\subsection{O protagonismo emancipatório do Novo Constitucionalismo Latino-Americano}

O novo constitucionalismo latino-americano emana do movimento desses sujeitos negados, ocultados e de seus anseios, e como tal, propõe-se transformador, objetivando dar as respostas que o Neoconstitucionalismo foi incapaz de conceder. O Novo Constitucionalismo

\footnotetext{
${ }^{3}$ A fim de corroborar os argumentos antes expendidos, veja-se a lição de Cenci e Bedin: ... cabe destacar a diferença (e, mais do que isso, a desigualdade) existente entre os lugares historicamente ocupados, por exemplo, pela Europa e pela América Latina, o que se reflete, evidentemente, nas histórias constitucionais: se, de um lado, o constitucionalismo europeu conviveu tranquilamente com a manutenção de colônias de exploração (o que evidencia uma absurda dissintonia entre os discursos constitucionais europeus e as práticas disseminadas no âmbito das colônias), os países latino-americanos estiveram, de outro lado, na condição de explorados cultural e economicamente. Enquanto os países europeus e os Estados Unidos da América incorporavam politicamente os ideais liberais, consolidando o Estado de Direito e as Constituições nacionais, fundadas em processos revolucionários, a América Latina ostentava uma realidade social escravagista, desigual e uma organização política absolutamente subordinada aos países europeus colonizadores - especificamente, no caso, Espanha e Portugal (2013,
} p. 29). 
Latino-americano, em contraposição ao Neoconstitucionalismo, pode ser entendido adequadamente dentro do que Santos convencionou chamar de cosmopolitismo subalterno:

O cosmopolitismo subalterno contém uma promessa real apesar de o seu caráter ser de momento claramente embrionário. De facto, para captá-lo é necessário realizar o que chamo de sociologia das emergências. Esta consiste numa amplificação simbólica de sinais, pistas e tendências latentes que, embora dispersas, embrionárias e fragmentadas, apontam para novas constelações de sentido tanto no que respeita à compreensão como à transformação do mundo. $\mathrm{O}$ cosmopolitismo subalterno manifesta-se através das iniciativas e movimentos que constituem a globalização contra-hegemônica. Consiste num vasto conjunto de redes, iniciativas, organizações e movimentos que lutam contra a exclusão econômica, social, política e cultural gerada pela mais recente incarnação do capitalismo global, conhecido como globalização neoliberal. [...]

A novidade do cosmopolitismo subalterno reside, acima de tudo, em ter um profundo sentido de incompletude, sem contudo ambicionar a completude. Por um lado, defende que a compreensão do mundo excede largamente a compreensão ocidental do mundo e, portanto, a nossa compreensão da globalização é muito menos global que a própria globalização. Por outro lado, defende que quanto mais compreensões não-ocidentais forem identificadas mais evidente se tornará o facto de que muitas outras continuam por identificar e que as compreensões híbridas, que misturam componentes ocidentais e nãoocidentais, são virtualmente infinitas. O pensamento pós-abissal parte da ideia de que a diversidade do mundo é inesgotável e que esta diversidade continua desprovida de uma epistemologia adequada. (SANTOS, 2010, p.50-51)

Nesse sentido, os povos sul-americanos são responsáveis pelo alvorecer de movimentos sociais que pressuporiam as bases para o movimento constitucional denominado como Novo Constitucionalismo Latino-americano.

De acordo com tais argumentos, enquanto o neoconstitucionalismo prima pela unicidade e igualdade formal, dispensando a diversidade e plúrimas formas de vida, pelo que deixa de efetivar direitos humanos mínimos aos povos tradicionais, o novo constitucionalismo latino americano tem como vocábulo básico a pluralidade, a diversidade. Esse constitucionalismo transformador visa resgatar os sujeitos negados, enquanto protagonistas dentro do Estado e de suas vidas, incluindo-se nesse rol de sujeitos a própria natureza.

Em verdade, pode-se dizer que novas perspectivas constitucionais que direcionam as ações do Estado e da própria sociedade em prol de uma integração entre diferentes povos, é característica principal do movimento denominado Novo Constitucionalismo Latino-americano. Tal movimento, procura legitimar constitucionalmente anseios e peculiaridades próprias dos povos latinos, a fim de aproximar as regras magnas de um país ao ideário real de seu povo. Nesse sentido, sustenta-se que no estágio atual da sociedade os novos paradigmas do Estado Contemporâneo na América Latina - os quais contemplam o processo de descolonização dos povos em todas as suas acepções - busca incessantemente o reconhecimento dos aspectos socioculturais dos povos latinos originários no plano formal e material.

A possível refundação da figura estatal no âmbito da América Latina poderia ser demonstrada através de uma escala evolutiva, a qual é apresentada por Wolkmer da seguinte forma: o desenvolvimento inicial do novo constitucionalismo latino-americano iniciou-se por intermédio de um primeiro ciclo que reúne as Constituições do Brasil (1988) e da Colômbia (1991), caracterizado por positivar ideais de ordem social e por seu caráter descentralizador. Logo, o segundo ciclo abarcaria a Constituição da Venezuela (1999), caracterizado sumariamente por ser um constitucionalismo participativo popular e pluralista. Já o terceiro ciclo representar-seia pelas Constituições do Equador (2008) e da Bolívia (2009) em que então se afirma a 
plurinacionalidade comunitária, destacando-se aqui a imponência da América do Sul enquanto formadora de bases sólidas para o desenvolvimento do novo constitucionalismo latino-americano (WOLKMER, FAGUNDES, 2011).

Sem dúvida alguma, o terceiro ciclo apresentado por Wolkmer é considerado como originário puro do novo constitucionalismo latino-americano, não havendo concordância quanto a considerar o primeiro e segundo ciclos como originários desse movimento, mas sim como precursores de características que posteriormente viriam a desencadear o novo constitucionalismo latino-americano. De qualquer forma, é imprescindível destacar as lições de Saldanha e Brum quando afirmam que na contemporaneidade pode-se observar a ocorrência de um processo duplo na seara do direito constitucional: o primeiro diz respeito a constitucionalização do direito internacional; e o segundo diz respeito a internacionalização do direito constitucional, ou sua desnacionalização (2015).

Assim, tal processo reflete a realidade constitucional latino-americana na atualidade, tendo em vista que o movimento denominado novo constitucionalismo latino-americano tem o condão de modificar positivamente a ordem constitucional da maioria dos países da América Latina, a fim de adequar os ordenamentos constitucionais à realidade e à historicidade do continente. Os autores prosseguem a análise referindo que o processo de internacionalização do direito constitucional ou de desnacionalização, consistem no reconhecimento em âmbito do direito internacional de determinadas funções materialmente constitucionais, salientando ainda que:

Esses movimentos circulares de abertura recíproca que colocam sob interrogação os limites impostos pelas fronteiras nacionais bem como a propalada autonomia do direito internacional, conduzem, inevitavelmente, ao reconhecimento de que o nacional não se sustém sozinho, quanto parece "ser nacional o futuro do direito internacional" diante da sua influência sobre as ordens nacionais (SALDANHA, BRUM, 2015, p. 197).

Frente a tais considerações, a Plurinacionalidade ${ }^{4}$ enquanto premissa basilar para consagração do Novo Constitucionalismo Latino-americano, revela o caráter não nacionalista e de abertura continental próprios desse movimento constitucional. Ademais, verifica-se que a o reconhecimento da plurinacionalidade e direitos dela supervenientes - como por exemplo a autonomia de povos indígenas ou tradicionais para gerir questões relacionados a sua cultura e seus saberes - configura-se como o ponto crucial para que se possa efetivamente reconhecer a vigência de um novo constitucionalismo latino-americano.

Tem-se que a plurinacionalidade enquanto pressuposto do novo constitucionalismo latino-americano revela-se como condicionante, além de elemento eficaz para a concretização de uma integração regional que se idealiza. A insurgência de novos parâmetros regionais que evidenciem em suas legislações constitucionais ideais que primam pela efetiva descolonização do território e consequente integração de seus povos, a fim de fortalecer a identidade e resgatar os aspectos culturais originários do povo da América Latina, é tarefa fadada ao Novo Constitucionalismo Latino-americano.

No que se refere ao Estado Plurinacional, Magalhães e Weil prelecionam:

\footnotetext{
${ }^{4}$ los grupos sociales en situaciones en que los derechos individuales de las personas que los integran resultan ineficaces para garantizar el reconocimiento y la persistencia de su identidad cultural o el fin de la discriminación social de que son víctimas. Como lo demuestra la existencia de varios Estados plurinacionales (Canadá, Bélgica, Suiza, Nigeria, Nueva Zelanda, etc.), la nación cívica puede coexistir con varias naciones culturales dentro do mismo espacio geopolítico, del mismo Estado. El reconocimiento de la plurinacionalidad conlleva la noción de autogobierno y autodeterminación, pero no necesariamente la idea de independencia. (SANTOS, , 2010, p. 81).
} 
A ideia de Estado Plurinacional pode superar as bases uniformizadoras e intolerantes do Estado nacional, onde todos os grupos sociais devem se conformar aos valores determinados na constituição nacional em termos de direito de família, direito de propriedade e sistema econômico entre outros aspectos importantes da vida social. Como vimos anteriormente o Estado nacional nasce a partir da uniformização de valores com a intolerância religiosa. [...] A grande revolução do Estado Plurinacional é o fato que este Estado constitucional, democrático participativo e dialógico pode finalmente romper com as bases teóricas e sociais do Estado nacional constitucional e democrático representativo (pouco democrático e nada representativo dos grupos não uniformizados), uniformizador de valores e logo radicalmente excludente. $\mathrm{O}$ Estado Plurinacional reconhece a democracia participativa como base da democracia representativa e garante a existência de formas de constituição da família e da economia segundo os valores tradicionais dos diversos grupos sociais (étnicos e culturais) existentes (MAGALHÃES, WEIL, 2010).

Portanto, enquanto movimento constitucional representado na contemporaneidade pelas constituições do Equador (2008) e Bolívia (2009) em sua escala mais desenvolvida, o novo constitucionalismo latino-americano configura-se como um arcabouço jurídico-constitucional com base democrática e pluralista construída sob terreno sólido, inovando no ámbito dos movimentos constitucionais regionais. Prova disso é a constitucionalização das cosmovisões dos povos indígenas originários da América do Sul, traduzidas pelo bem viver: próprias dos quíchuas na Constituição do Equador e dos aimarás na Constituição da Bolívia (2009, p. 03).

Frente a essas considerações, pode-se dizer que, visando contrapor a lógica eurocêntrica impregnada nos ditames sociojurídicos da América Latina, conflitos de ordem sociológica passam a emoldurar uma nova fase constitucional no continente, a qual pretende aproximar a realidade e as peculiaridades latino-americanas dos comandos constitucionais. Assim, o movimento denominado novo constitucionalismo latino-americano configura-se como aporte sociojurídico empoderador dos povos sul-americanos, cujas lutas sociais desaguam em um movimento constitucional que prima pelos direitos humanos de seus povos levando em conta suas identidades, originalidades e necessidades.

\subsection{O Novo Constitucionalismo Latino-Americano enquanto ferramenta legitimadora dos Direitos Humanos dos povos Sul-Americanos}

Afora o protagonismo emancipatório próprio do novo constitucionalismo latinoamericano, é necessário salientar seu papel como efetiva vertente constitucional para o reconhecimento e legitimação dos direitos humanos dos povos sul-americanos ${ }^{5}$. Nesse diapasão, o fato desse movimento constitucional possuir como vertente o pluralismo jurídico e desaguar na

\footnotetext{
${ }^{5}$ Las Constituciones de Ecuador y Bolivia se proponen una refundación del Estado a partir del reconocimiento explícito de las raíces milenarias de los pueblos indígenas ignorados en la primera fundación republicana, y por ende se plantean el reto histórico de poner fi n al colonialismo. Los pueblos indígenas son reconocidos no sólo como "culturas diversas" sino como naciones originarias o nacionalidades con autodeterminación o libre determinación. Esto es, sujetos políticos colectivos con derecho a defi nir su destino, gobernarse en autonomías y participar en los nuevos pactos de Estado, que de este modo se confi gura como un "Estado plurinacional". Al defi nirse como un Estado plurinacional,

resultado de un pacto entre pueblos, no es un Estado ajeno el que "reconoce" derechos a los indígenas, sino que los colectivos indígenas mismos se yerguen como sujetos constituyentes y, como tales y junto con otros pueblos, tienen poder de defi nir el nuevo modelo de Estado y las relaciones entre los pueblos que lo conforman. Es decir, estas Constituciones buscan superar la ausencia de poder constituyente indígena en la fundación republicana y pretenden contrarrestar el hecho de que se las haya considerado como menores de edad sujetos a tutela estatal a lo largo de la historia (FAJARDO, 2011, p. 148).
} 
propulsão da plurinacionalidade em sua fase recente, demonstram que o reconhecimento da diversidade e do pluralismo no âmbito jurídico consistem em ideais que redescobrem a necessária legitimação de direitos humanos imprescindíveis à grupos não hegemônicos - mas não necessariamente minoritários -, como os indígenas e afrodescendentes.

Ademais, tem-se como inauguração de um novo momento constitucional o pluralismo identificado pelo reconhecimento de idiomas indígenas, da educação intercultural e o advento de novas formas de participação sociopolítica. Não se pode olvidar ainda, que na fase mais recente do Novo Constitucionalismo Latino-americano, tem-se a atuação direta de grupos não hegemônicos na luta pela efetivação de direitos humanos consagrados constitucionalmente, através de mecanismos que ampliam a participação destes e democratizam a participação jurídico-política dos povos na construção do Estado de Direito.

Para tanto, promove a recuperação e releitura da categoria "soberania popular", no sentido de refundar o Estado, promovendo a participação direta do povo na elaboração e aprovação da constituição, bem como no controle e gestão da administração. 6. Estabelece instituições paralelas de controle baseadas na participação popular: "Poder Cidadão" (Venezuela), "Controle Social" (Bolívia) e o "Quinto Poder" (como ficou conhecido no Equador).

Revela o fenômeno da "Glocalização", que une o global ao local, em um processo que conjuga a integração internacional e o redescobrimento de valores, tradições e de estruturas locais e particulares. 9. Procura promover um novo modelo de integração latino-americana, superando o isolacionismo intercontinental de origem colonial. A integração passa a ter, igualmente, um conteúdo social mais acentuado. 10. Garante o poder de intervenção pública na economia, em oposição ao modelo de intervenção privada neoliberal (VIEIRA, 2009, p. 15).

Dessa forma, o que esse novo constitucionalismo latino-americano se propõe é redefinir a linguagem acerca dos direitos humanos, ou melhor, é uma proposta de emancipação dos Direitos Humanos originalmente formulados na base ocidental. Para Santos a plurinacionalidade observada a partir dessa releitura dos Direitos Humanos implica no reconhecimento dos Direitos coletivos dos povos e grupos sociais (SANTOS, 2015, p.189). Em igual sentido, Claveró afirma que "o que está sendo colocado, em definitiva, é uma nova antropologia para os direitos humanos, uma antropologia de base mais humana que aquela que representaram até agora tanto o direito constitucional quanto o direito internacional" (CLAVERÓ, 2015, p.125).

Nesse interím, por meio de lutas sociais que objetivariam promover o reconhecimento das identidades dos povos pela figura estatal, o arcabouço constitucional da América Latina passa a ser constantemente transformado. A aproximação da realidade do continente com as cartas constitucionais originam um processo sociojurídico que permite o avanço da legislação constitucional em contextos nos quais os elementos constitucionais eurocêntricos até então vigentes, mostraram-se estagnados.

Portanto, o protagonismo dos povos sul-americanos enquanto condição determinante para o surgimento do Novo Constitucionalismo Latino-americano consiste também em condição preponderante para a consagração de textos constitucionais comprometidos com os direitos humanos próprios da realidade latino-americana, ou seja, que levam em conta as necessidades, originalidades e peculiaridades de seus povos.

Em contexto similar ao do Caracaço, inserem-se, também, a chamada "Guerra do Gás” (em 2003, na Bolívia) e os protestos ocorridos no Equador (2005). Reunidas, as três revoltas populares foram o estopim de um movimento jurídico batizado com o nome de "Novo Constitucionalismo Latino-Americano" ou "Un constitucionalismo sin Padres". Esse novo constitucionalismo parece ter seu 
marco zero normativo com a promulgação da Constituição da República Bolivariana da Venezuelana (1999), desdobrando-se e desenvolvendo-se com as novas constituições do Equador (2008) e da Bolívia (2009). Suas raízes históricas, contudo, são mais profundas, e penetram séculos de história sulamericana e mundial. Nesse sentido, o novo constitucionalismo parte de postulados clássicos da teoria constitucional, repetindo, por exemplo, o tradicional catálogo de direitos de proteção individual. Por outro lado, procura superar o constitucionalismo clássico no que este não teria avançado, sobretudo no que se refere às possibilidades de articulação e releitura da categoria soberania popular, como condição necessária de legitimação das instituições e de gestão do próprio Estado. Indo mais longe, o Estado deverá ser refundado sobre os escombros das promessas liberais não cumpridas, promovendo-se sua reconstrução a partir de uma "nova geometria do poder (VIEIRA, 2009, p. 02)".

Assim, a implantação de mecanismos atinentes a democracia participativa, a integração dos povos e a implantação de uma nova concepção do papel da sociedade frente ao Estado e viceversa, são exemplos de princípios intrínsecos ao novo constitucionalismo latino-americano. Ademais, o novo constitucionalismo latino-americano possui como premissa basilar a positivação de direitos que permitem a consagração dos direitos humanos sob uma acepção que leva em conta as originalidades dos povos que compõem cada Estado, tendo como pressuposto básico o pluralismo jurídico e, em sua mais nova fase o reconhecimento da plurinacionalidade.

Em verdade, esse movimento constitucional é capaz de revelar uma imbricação de elementos próprios do novo constitucionalismo latino-americano pois, ao mesmo tempo em que se está diante de processos constitucionais próprios de cada Estado, levando em conta questões atinentes à soberania e aos aspectos internos de cada país; se está também diante de problemáticas comuns à América Latina, de forma que qualquer ferramenta constitucional inerente a resolução de problemas sociopolíticos ou econômicos internamente ressoa as diversas questões próprias do processo de colonialidade impostas ao continente como um todo.

As tendências atuais da América Latina remetem sem dúvida alguma, à união dos estados latino-americanos visando à congregação de esforços para a construção de uma nova ordem política e social que preze o reconhecimento da identidade e cultura de seus povos, inerente ao processo de descolonização, ao reconhecimento dos direitos humanos próprios do continente e à uma nova ideia de desenvolvimento. Sob esse aspecto, há que salientar que as inovações sociojurídicas próprias do Novo Constitucionalismo Latino-americano, concernentes a busca de um novo papel da sociedade no Estado e a integração de povos não hegemônicos e marginalizados, refletem o despertar, sobretudo da América do Sul, para a consagração de um movimento constitucional que direciona o continente para uma integração regional, visando superar barreiras nacionalistas para enfrentar os desafios pertinentes a efetivação de direitos humanos próprios dos povos que compõem o continente.

De acordo com tais argumentos, se por um lado se está diante de textos constitucionais próprios e fiéis à estrutura jurídico-normativa de cada país, levando em conta as peculiaridades de cada Estado; por outro de está diante de conexões constitucionais comuns e integradas, principalmente no que diz respeito a necessidade de uma vigência efetiva dos direitos humanos dos povos sul-americanos. Nesse sentido, justamente por constitucionalizar as originalidades próprias de seus povos "o novo constitucionalismo mereça ser denominado latino-americano (SOUSA, 2016, p. 09). 


\section{CONCLUSÃO}

As reflexões críticas induzidas pela investigação realizada, sobretudo nos remete para a necessidade de construção de aportes sociojurídicos comprometidos com a realidade da América do Sul. Sendo as normas constitucionais ferramenta que delineia as bases jurídico-administrativas de um Estado, movimentos constitucionais devem possuir olhares que venham a refletir a identidade de seu povo a fim de que as bases constitucionais de um Estado sejam desde e para o seu povo. Movimentos constitucionais incongruentes, cartas constitucionais não comprometidas com a realidade sociojurídica no tempo e no espaço, carecem de efetividade e revelam-se como meros aportes tecnicistas.

Foi sob tais paradigmas que o primeiro capítulo do presente artigo procurou revelar que a história constitucional da América do Sul é marcada substancialmente pelo respaldo de interesses eurocêntricos, estranhos às peculiaridades sul-americanas. Assim, respaldado pelo processo de colonização o Neoconstitucionalismo sustenta o processo de colonialidade na era contemporânea, garantindo que diretrizes desenvolvimentistas sejam elementos jurídicos paradigmáticos na América do Sul. Com isso, direitos humanos positivados constitucionalmente são, não raras vezes, estranhos às peculiaridades dos povos sul-americanos e totalmente inefetivos.

Frente a essa realidade é que se objetivou analisar novas perspectivas de efetivação dos direitos humanos dos povos sul-americanos a partir do movimento constitucional denominado como Novo Constitucionalismo Latino-americano. Tem-se o alcance de tal objetivo por meio da verificação de que o Novo Constitucionalismo Latino-americano figura na contemporaneidade como protagonista emancipatório dos povos sul-americanos, concedendo novas observações para a consagração constitucional dos direitos humanos que se sustentam pelo comprometimento do texto constitucional com os povos que gestacionaram um movimento constitucional desde e para a América do Sul.

Em vista de tais considerações, buscando sanar a indagação que induziu a presente pesquisa, tem-se que os limites para a construção de novas percepções acerca dos direitos humanos dos povos sul-americanos a partir das inovações próprias do novo constitucionalismo latino-americano, são aquelas que se aliam a perspectivas eurocêntricas e em conformidade com o processo de colonialidade. As possibilidades são aquelas que se alinham perfeitamente com o sentido subjetivo do Novo Constitucionalismo Latino-americano e suas finalidades precípuas.

Sob tais argumentos, verificou-se que para além de novas perspectivas para a efetivação, o Novo Constitucionalismo Latino-americano atua como ferramenta legitimadora dos direitos humanos dos povos da América do Sul. Assim, a consagração do Novo Constitucionalismo Latino-americano enquanto movimento constitucional que se assenta nas constituições de Bolívia e Equador inaugura uma espécie de integração regional sul-americana a partir de novas percepções para os direitos humanos dos povos sul-americanos.

\section{REFERÊNCIAS BIBLIOGRÁFICAS}

BRAGATO, Fernanda Frizzo; CASTILHO, Natalia Martinuzzi. A importância do póscolonialismo e dos estudos descoloniais na análise do novo constitucionalismo latino-americano. In: VAL, Eduardo Manuel (org.); BELLO, Enzo (org.). O pensamento pós e descolonial do novo constitucionalismo latino-americano. Caxias do Sul/RS: Educs, 2014.

CARBONELL, Miguel. El Neoconstitucionalismo en su labirinto. In: CARBONELL, Miguel (org). Teoría del neoconstitucionalimo: ensayos escogidos. Madrid: Editorial Trotta, 2007. 
CENCI, Ana Righi. BEDIN, Gilmar Antônio. O Constitucionalismo e sua Recepção na América Latina, Uma leitura das fragilidades do Estado constitucional na região e suas novas possibilidades de realização. In Direitos Emergentes na Sociedade Global - Anuário do Programa de Pós-Graduação em Direito da UFSM, 2013.

DANTAS, Ivo. A pós-modernidade como novo paradigma e a teoria constitucional do processo. In: MOURA, Lenice S. Moreira de (org). O novo constitucionalismo na era pós-positivista: homenagem a Paulo Bonavides. São Paulo: Saraiva, 2009.

FAJARDO, Raquel Z. Yrigoyen. El horizonte del constitucionalismo pluralista: del multiculturalismo a la descolonización. In El derecho en América Latina: un mapa para el pensamiento jurídico del siglo XXI. Org. GARAVITO, César Rodríguez. Buenos Aires: Siglo Veintiuno Editores, 2011.

FERNANDES, Bernardo Gonçalves. A teoria da constituição à luz dos movimentos do constitucionalismo (moderno), do Neoconstitucionalismo (contemporâneo), do transconstitucionalismo e do constitucionalismo (latino-americano) plurinacional. In: MORAIS, José Luis Bolzan (org.). BARROS, Flaviane de Magalhães (org.). Novo constitucionalismo latino-americano: o debate sobre novos sistemas de justiça, ativismo judicial e formação de juízes. Belo Horizonte: Arraes Editores, 2014.

FIGUEIREDO, Eduardo Henrique Lopes de. Entre Política e Normatividade: Constitucionalismo, Direitos Fundamentais e Democracia na Era das Consequências. In: Revista de Direito Brasileira, Vol. 12, 2015. Disponível em: <http://www.rdb.org.br/ojs/index.php/rdb/article/view/356/219> Acesso em: 23 de maio de 2017.

GONZÁLEZ CASANOVA, Pablo. Colonialismo interno (uma redefinição). In: A teoria marxista hoje: problemas e perspectivas. Org: BORON, Atilio A.; AMADEO, Javier; GONZALEZ, Sabrina. 2007. Disponível em: 〈http://bibliotecavirtual.clacso.org.ar/ar/libros/campus/marxispt/cap. 19.doc>. Acesso em: $07 \mathrm{de}$ março de 2017.

JULIOS-CAMPUZANO, Alfonso de. Constitucionalismo em tempo de globalização. Tradução: José Luis Bolzan de Morais; Valéria Ribas do Nascimento. Porto Alegre: Livraria do Advogado, 2009.

LASSALLE, Ferdinand. O que é uma Constituição?. Tradução: Hiltomar Martins Oliveira. Belo Horizonte: Cultura Jurídica, Editora Líder, 2001.

MAGALHÃES, José Luiz Quadros de. WEIL, Henrique. Bioética no Estado de Direito Plurinacional. Disponível em: http://jus.com.br/artigos/14151/bioetica-no-estado-de-direitoplurinacional - Acesso em 20 de novembro de 2015.

QUIJANO, Aníbal. Colonialidade do poder, eurocentrismo e América Latina. In: A colonialidade do saber: eurocentrismo e ciências sociais - perspectivas latino-americanas. Buenos Aires: Clacso, 2005. Disponível em: $<$ http://biblioteca.clacso.edu.ar/clacso/sursur/20100624103322/12_Quijano.pdf>. Acesso em: 10 de outubro de 2016.

SALDANHA, Jânia Maria Lopes. BRUM, Márcio Morais. A margem nacional de apreciação e sua (in)aplicação pela Corte Interamericana de Direitos Humanos em matéria de anistia: uma 
figura hermenêutica a serviço do pluralismo ordenado? Anuario Mexicano de Derecho Internacional. Vol. XV, 2015.

SANTOS, Boaventura de Sousa. Refundación del Estado en América Latina: perspectivas desde una epistemología del Sur. Lima: Instituto Internacional de Derecho y Sociedad, 2010.

SANTOS, Boaventura de Souza Santos. Para além do pensamento abissal: das linhas globais a uma ecologia de saberes. In: SANTOS, Boaventura de Souza (Org); MENESES, Maria Paula. Epistemologias do Sul. São Paulo, Cortez: 2010.

SANTOS, Boaventura de Souza. Para um novo senso comum: a ciência, o direito e a política na transição paradigmática. São Paulo: Cortez, 2011.

SOUSA, Adriano Corrêa de. A libertação como objetivo central do novo constitucionalismo latino-americano: os caminhos para um constitucionalismo da libertação. Disponível em: http://www.publicadireito.com.br/artigos/?cod=3bd7ef30b1a12dc7 - Acesso em 22 de setembro de 2016.

VIEIRA, José Ribas. RODRIGUES, Vicente A. C. Refundar o Estado: o novo constitucionalismo latino-americano. Disponível em: http://www.direito.ufg.br/up/12/o/24243799-UFRJ-Novo-Constitucionalismo-LatinoAmericano.pdf?1352146239 - Acesso em 22 de fevereiro de 2017.

WOLKMER, Antonio Carlos; FAGUNDES, Lucas Machado. Tendências contemporâneas do constitucionalismo latino-americano: Estado plurinacional e pluralismo jurídico. In: Pensar, Fortaleza, v. 16, n. 2, p. 371-408, jul./dez. 2011. 